\title{
The Effect of Task Type on the Choice and Use of Communication Strategies by Algerian EFL Learners in Spoken Discourse
}

\author{
Nadia Zerrouki \\ Department of English, Faculty of Foreign Languages, University of Jordan, Amman, Jordan \\ Prof.Rajai Al-Khanji \\ Faculty of Foreign Languages, University of Jordan, Amman, Jordan
}

\begin{abstract}
The present study aimed to investigate the impact of task types on the use of communication strategies (CSs) by (30) Algerian learners of English as a foreign language (EFL) in spoken discourse at the University of M'Hammed Bouguerra in Boumerdes.Data was collectedfrom audio recordings of scenario and interview tasks have been classified according to a taxonomy compiled from previous taxonomies of such strategies, and more specifically those of Dörnyei and Scott (1997), and Faerch and Kasper (1983). Descriptive and inferential analysiswere conducted to investigate the effect of task types on the choice and use of CSs. The frequency and percentage of each strategy in the two tasks were calculated. In addition, SPSS program was used to answer the second research question which deals with the effect of task on the choice and use of CSs. The t-test for independent samples is used to calculate the means and the standard deviations in order to examine any significant differences between the scenario and interview that may result from the task type variation. The results indicates thatthe task type has an impact on the choice and use of CSs particularly influenced by the interview.It reveals that the difficulty of interview demands more linguistic items which lead to the use of specific strategiesand wide range of CSs. The effect of task was more significant in the use of CSs than their choice.
\end{abstract}

Keywords: Communication strategies (CSs), choice and use of CSs, and task type (interview and scenario).

DOI: $10.7176 / \mathrm{JEP} / 11-30-08$

Publication date:October $31^{\text {st }} 2020$

\section{Introduction}

Communication strategies have become an essential and significant component of the communicative competence that a second or foreign language learners need in order to express their ideas effectively as Canale and Swain (1980) stated.In addition, CSs enable those learners to overcome their problems and deficiencies when communicating. Selinker (1972)states that CSs are the means used by foreign and second language learners to solve problems that face them in the process of communication. In other words, communication strategy is "an individual's attempt to find a way to fill the gap between their communication effort and immediate available linguistic resources." (Maleki, 2010 p.1).

The crucial role of CSs in enhancing foreign language learners' oral proficiency has been receiving much attention by the researchers specialized in the field of communication. Thus, many studies were conducted about that (e.g. Tarone 1981; Dörnyei and Scott 1997; Rababah and Bulut 2007; Rababah, 2016 and Ahmed 2018). CSs have been studied by several Algerian scholars likeGhout-Khenoune 2012; Ait-Eldjoudi 2015; and Alloui 2015. These studies have made an essential contribution to L2 English acquisition, but further research is needed in this context. More specifically, the impact of task type on the choice and use of CSs was rarely investigated in the Algerian context. Therefore, the present paperfills a gap in the relevant literature. That is because the present study attempts to explore the CSs used by Algerian EFL learners in oral discourse. This may increase our knowledge of which CSs are employed by them. It also examines whether different tasks (scenario and interview) affect their choice and use of CSs.

\subsection{Definitions and Taxonomies of CSs}

The term CSs was introduced by Selinker (1972) in his paper 'Interlanguage". He referred to it in the field of second language acquisition and learning to mean the ways in which foreign or second language learners' deal with communication breakdowns when they face problems of linguistic choice and abilities. Tarone (1981-1983) providesdifferent definitions for the term (CSs)which convey one common meaning that CSs are employed by learners to solve problems in daily life or classroom conversations. He states that they are 'Learners' attempt to bridge the gap between their linguistic competence in the target language and that of the target language interlocutors.'” (ibid, p. 288).

Faerch and Kasper (1983, p. 20) defineCSs as "conscious plans to overcome the problems facing an individual to reach the intended meaning of communication process." They view them as ways of overcoming communication difficulties. According tothem, communication problems can be solved by avoiding and changing communicative goals, or by reducing the original objective. As a result, two mainclassifications of CSs types were 
introduced (ibid, p.52)which are "reduction strategies" where the learners avoid producing incorrect utterances by using means of reduced system, "achievement strategies" where the learners expand their communicativeand linguistic resourcesto overcome communicative breakdowns.Bialystok (1990) linked CSs to problem and solution in the communication process.

Dörnyei and Scott (1997) classified CSs into three types. The first type is represented in the direct strategies that are employed by speakers when they face difficulties during communication process. They attempt to overcome them directly by avoiding problems or using other devices that help learners to convey the right message such as (paraphrasing or switching into native language). The second type is represented in the indirect strategies that are used by them in case of providing the conditions that lead to the mutual understanding or strategies that speakers use to gain time and keep communication process open such as, time fillers. The third type is represented in the interactional strategiesthat are used to reach the mutual cooperation between the speakers who help each other to send and receive the meaning for instance, appeal for help or asking for clarification. (ibid, p. 177- 180). Indeed, CSs were defined depending on different approaches and theories (Numata, 2009). Therefore, they are of several classifications and types.

\subsection{Studies on Task Type and CSs Use}

The impact of the task type on the choice and use of CShas been receiving the attention of several researchers. Those researchers aimed to explore whether the nature of tasks affects the speaker's choice and use of the communication strategy or not. Several researchers found that there is a significant relationship between the task type and the use of CSs by learners (e.g. Rababa'h and Seedhouse, 2004; Rababa'h and Bulut, 2007; and GhoutKhenoune, 2012).

Poulisse and Schils (1989) conducted a study on Dutch learners of English. Theyinvestigated the effect of proficiency level and task type on their use and choice of CSs.Picture description, a story retelling task performed individually, and interview with a native speaker (NS) were examined. The latter scholars found that the task had an impact on the choice of CSs used by theselearners. Theyfound that the task focus and demands, context, time and interlocutor were among the variables that lead to these differences. They added that thetask influenced their choice and use morethan the learners' proficiency did.

Rababa'h and Bulut (2007) investigated the effect of task type on the use of CSs ininterview and role-play. Based on the findings, learners resorted to a large number of CSs in in the interview. They justified this result by stating that the task demands and its difficulty lead learners to use a wide range of CSs and vocabulary use. Whereas, in the roleplay, the participants did not employ many CSs, because they were limited by communication turns in a closed-ended task.

Ghout-Khenoune (2012) conducted a study about the effect of task type on learners' use of CSs. She aimed to find out the CSs that were used by a group of second year Universitystudents of EFL and to understand the link between the use of these strategies and two different tasks which were free discussion and object description. The sample of this study was sixteen second year students of English at the University of Algiers. The ages of the members of the sample are within the range of (nineteen and twenty five years old). The data was collected through using task elicitation and non-participant observation using a camcorder. She analyzed the data applying Tarone's (1981-1983) and Bialystok's (1983) taxonomies. The results showed that students employed various strategies and tasks affected their use in terms of quantity, but not quality.

Shtavika (2018)aimed to explore the role of task type on the use of CSs by Kosovan's and Bosnian's speakers of English. Thestudy's sample consists from (20)students who use English as a foreign language. The members of the sample are divided into (i.e. Elementary andIntermediate) based on their proficiency levels in English. The latter researcher collected data using three different tasks: ten minutes of oral communication, picture story narration and photographic description. She collected data from audio and video-recorded the data.She applied Tarone's (1977) taxonomy in classifying CSs that were employed by the learners. She found out thatthe task type and the level of proficiency affectedthe choice and the frequency of CSs in oral performances. She observed that context and task demands influenced their quality.

Rosas (2018) investigated the role of the task type on Spanish L2 learners' strategic communication in faceto-face interactions with other learners and native speakers (NSs) of Spanish. Thestudy's sample consists from 24 English speakers learning Spanish at a University in Liverpool(21 females and 3 males). Their ages of the members of the same are within the range of eighteen - twenty sixyears, except for six females and one male students with ages ranging from twenty five to thirty five years. They shared the same proficiency level in English. In two different tasks of Jigsaw and a free-conversation activity, she collected the data of study from thirty six interactions between Spanish L2 learners and native speakers of Spanish. Thedata was collected from video and audio recordings, observation of participants' interactions and stimulated recall methodology.The latter researcher analyzed the data based on Dörnyei and Körmos' taxonomy (1998) and the interactional CSs from Dörnyei and Scott's (1997). She conducted quantitative and qualitative analysis. The results revealed that the task type influenced the use of CSs by learners particularly the Jigsaw task. The latter researcher found that the task objective 
and focus affected the use of certain CSs in order to fulfil the demands of each task. Through observation, it was found that the jigsaw required linguistic demands, and the free-conversation needed cognitive requirements and this played a role in the learners' use of specific CSs.

The pre- existing studies in this context suffer from some limitations such as the sampling which is not large, the taxonomies adopted were ancient in addition to the type of analysis which was more qualitative. Therefore,the present study aimed to identify the CSs used by Algerian EFL learners. It aimed to explore the effect of task type on the choice and use of CSs. It aimed to determine whether there is any difference or similaritybetween the two tasks of interview and scenario in the choice and use of strategies.

\section{Research Objectives}

Based on the related literature, few studies aimed to identify the CSs that are employed by the Algerian EFL learners. As far as the researcher's know, the effect of task on the choice and use of CSs hasn't been investigated much by researchers. Therefore, the current study fills a gap in the relevant literature. It aimed at identifying the CSs employed by a sample of thirty EFL second year learners of English. It alsointended to explore the relationship between the choice and use of CSs in the two communicative tasks: interview and scenario.

\section{Research Questions}

The study aims to answer the following questions:

Q.1. What are the communication strategies used by Algerian EFL learners in oral discourse?

Q.2.Are there statistically significantdifferences in choosing and using the communication strategies of the interview and scenario?

\section{Research Methodology \\ 5.1 Sample}

The sample consists from (30), (28 females and 2 males) second year students of English enrolled in the LMD system at the Department of Foreign Languages and Literature, at the University of M'Hammed Bougerra, Boumerdes. The ages of the respondents are within the range of (19) -(22) years, except for two participants with the age of (32) and (50) years old. All the respondents are native speakers of Arabic. They speak French and Kabyle as L2 languages and English as a foreign language. Indeed, the department for us is a convenient place that makes things easier to get access of thestudents and teachers at the same time, and thus conduct and answer our research questionsas accurately as possible.

\subsection{The Research Design, Data Collection Methods and Analysis}

The researchers aimed to explore the CSs used by the Algerian EFL learners and the impact of task on their choice and use. Thus, scenario and interview tasks are used to elicit the data. Recordings from these tasks are used. What follows is a detailed description of these tools and procedures used to collect data by providing the major steps followed in the present study.

\subsubsection{The Scenario Task-}

The subjects are divided into sub-groups of three or four students.It is easy for the teacher to examine and test his/her students in such conditions. The same applies to the researchers of the present study. Learners are given a list of scenarios to select one. This is an example of one of the scenarios which is given to students.

Scenario title: A job outside Algiers

"You have been offered a new job and a promotion at the University of M'Hammed Bouguerra in Boumerdes. This means that your family will have leave to Boumerdes with you. However, your wife and children do not want to move. Should you accept the position in Boumerdes and advance in your career or should you stay in Algiers to please your family without any job promotion for the rest of your life? How can you convince your family withyour plan?'”.

Learners are asked to play different roles. For instance, in this scenario students A and B agree to leave Algiers. As for the two others, they reject the idea and make an argument against their colleagues. As a matter of fact, the teacher explains the situation. He must use Arabic a little in order to make sure that the subjects understand their roles. In the majority of scenarios, we have always like a debate, two learners against two or three others. It gives students opportunities to speak more and use a greater number of CSs. They are given few minutes to agree on the roles and prepare themselves for the conversation. The phone recorder is switched on. Even though, students are given the chance to record themselves to check their errors and develop speaking abilities. These instructions make students feel free to talk. Then,learners are asked to start the scenario and play their roles in English. Finally, the students' oral production in L2 is recorded and transcribed in order to conduct an analysis later

\subsubsection{The Interview}

The second tool for collecting data in the oral test in addition to acting scenarios is giving the learners free questions in which they are asked to talk about different topics of their interest. Students are engaged in natural 
communication, where they talk about their problems, future plans, hobbies, happy and sad moments in their life ect...). At this point, the teacher provided thelearners with three or four questions to answer. The students were interviewed one by one. Finally, the students' speech was recorded and transcribed to be analyzed following the pre-existing taxonomies, more specifically Faerch \&Kasper (1983) and Dörnyei\&Scott (1997). They capture the verbal CSs. Descriptive and inferential statistical methodsare used to answer the questions of this study. Percentages and frequencies are used to identify the CSs used by the learners. In addition, the t-test is conducted to determine the link between the learners' CSs choice, use and the task type.

\section{Findings and Discussions}

6.1 Findings Related to Question 1: What are the communication strategies used by Algerian EFL learners in oral discourse?

The findings of question (1) show that the participants resorted to a large number of CSs. Almost all the strategies in Dörnyei's and Scott's (1997) taxonomy were found out in learners' speech.In fact, the learners employed(1410)instances in the two communicative tasks of scenario and interview. The table below presents the frequencies and percentages of these strategies. The ones used the most are presented first.

Table (1): CSs Used by the Algerian Students in Scenario and InterviewTasks

\begin{tabular}{|c|c|c|c|c|c|}
\hline \multirow{2}{*}{ Strategy } & Scenario & Interview & \multirow[b]{2}{*}{ Total } & \multirow[b]{2}{*}{ Percentage } & \multirow[b]{2}{*}{ Rank } \\
\hline & Frequency & Frequency & & & \\
\hline Repetition & 333 & 346 & 697 & $48.5 \%$ & 1 \\
\hline Code switching & 18 & 154 & 172 & $12.2 \%$ & 2 \\
\hline Use of fillers & 96 & 54 & 150 & $10.6 \%$ & 3 \\
\hline Use of all-purpose words & 9 & 50 & 59 & $4.2 \%$ & 6 \\
\hline Self- correction & 10 & 15 & 25 & $1.8 \%$ & 8 \\
\hline Message abandonment & 42 & 61 & 103 & $7.3 \%$ & 5 \\
\hline Topic avoidance & 4 & 18 & 22 & $1.6 \%$ & 10 \\
\hline Use of similar sounding words & 7 & 9 & 16 & $1.1 \%$ & 11 \\
\hline Approximation & 13 & 10 & 23 & $1.6 \%$ & 9 \\
\hline Literal translation & 42 & 66 & 108 & $7.7 \%$ & 4 \\
\hline Circumlocution & 1 & 9 & 10 & $0.7 \%$ & 12 \\
\hline Appeal for help & 3 & 35 & 38 & $2.7 \%$ & 7 \\
\hline Foreignising & 2 & 1 & 3 & $0.2 \%$ & 13 \\
\hline Word coinage & 2 & 0 & 2 & $0.1 \%$ & 14 \\
\hline Total & 582 & 828 & 1410 & $100 \%$ & \\
\hline
\end{tabular}

Based on table (1), (14) types of CSs are used by Algerian EFL learners. (580) CSs are found out in the task of scenario and (828) CSs in the interview. Notably, theyused many CSs when communicating in English.This result is consistent with Mabry (1994) who stated thatArab learners use more CSs than other speakers. This may be attributed to the differences that exist between English and Arabic languages.

One striking conclusion can be drawn is that may be the learners' low level in English which leads them to use a high number of CSs as Labarca and Khanji (1986) and Rababah (2001) claimed. They reportedthat the higher proficiencylevel is, the lower the use of CSs and vice versa. Rababah (2005) states that Arab learners of Englishface many difficulties, because they lack vocabulary-related knowledge and can't master all the linguistic resources in the target language. Thus, they do not always communicate in English effectively.

More interestingly, by carefully looking at table (1) above, it has been noticed that some CSs are used more frequently than others.It was found that the top five strategies employed by the learners are repetition, codeswitching, theuse of fillers, literal translation, and message abandonment. Based on Faerch and Kasper (1983), message abandonment and repetition are classified under the category of reduction strategies.

Thus, the findings of this analysis may indicate that the students are not competent in English. In fact,the students are not fluent and have low proficiency level in English. That is why they use reduction strategies. The latter results are consistent with the results concluded by Ahmed (2018). The latter scholar found that learners employreduction and L1 strategies more than achievement ones. Probably, Arab and Algerian EFL learners do not practice the English language in their daily lives.

Another important result of this table is the large number of repetition that the data yielded. (697) CSs aredetected in their oral production. It is the most frequent strategy with the percentage of $(48.5 \%)$. It is defined by Dörnyei and Scott (1997) as repeating a word or a string of words immediately after they are said.

For example, one student says: What, what? Travel! you are serious!.

This finding is considered with the finding reached by Khanji’s (1996). The latter scholar aimed to examine the CSs used by Jordanian EFL learners in spoken discourse, and comes with the conclusion that repetition was 
the highest communication strategy in their speech. That is probably attributed to the limited lexical items and the lack of linguisticresources. Another reason can be their low proficiency level. The system of Arabic language which differs from the one of English may be another justification for this result. In his respect, Arabic language has a repetitive style where native speakers of Arabic language are famous of being repetitive. So, the latter speakers like repetition and elaboration.

Additionally, table (1) shows that the code- switching strategyis ranked second in terms of the extent of using it (12.20\%), (172) occurrencesof this strategy are registered. These findings support those of Tan, Farizaand Jaradat (2012) who claimed that code- switching was the most frequent strategy and word coinage was the least used one in their study which investigated types and frequencies of CSs that are used by international learners at University Kebangsaan Malaysia. The students probably use code- switching because of the interference of mother tongue and lack of vocabulary items.

Dörnyei and Scott (1997) described code-switching asincluding L1/L3 words with L1/L3 pronunciation in L2 speech. This may involve stretches of discourse ranging from single words to whole chunks and even complete turns. This example is selected from our corpus to illustrate this strategy:

Student B says: you know five (05) years ... we have a life here a house / allahibarek / (God bless).

Its employment by the Algerian group can be linked to many reasons. First, possibly teachers allow theirlearners to use their mother tongue (Arabic/Kabyle) when communicating in English. In addition, teachers may resort to this strategy in the classroom. Second, the effect of mother tongue and French can play role in this case, especially that the majority of learners are proficient in these languages. Finally, their lack of lexical items and poor proficiency level may lead to the use of this strategy. In addition, fear of making errors, shyness and lack of confidence may motivate students to switch. This is an important result,because it shows that the participants used CSs rooted in previously learned languages, instead of resorting to other types of strategies that are related to the target language.

The data further indicates that the use of fillers is among the most prevailing strategies (10.60\%).Dörnyei and Scott (1997)define this strategy as the use of gambits to fill pauses, to stall and gain time in order to keep the communication channel open and maintain discourse at times of difficulty (well, actually, and you know). This is an example selected from the speech of the participants.

Student A: you know, you know I correct your paper sorry sorry.

In this regard, Hardianti (2016) found out that the use fillers is frequently used by learners in his study which examined CSs used by EFL learners at the University of Kuningan. Probably, it is used because of the lack of vocabulary or the topics that are not valid for some learners as he pointed out. One may justify this finding by stating that probably this strategy is taught and highlighted by teachers in Algeria.Furthermore, it can be used by learners to gain time in case of communication breakdown.

Furthermore, literal translation and message abandonment were also among the most frequently used strategies. One hundred eight cases of literal translation were observed, and (103) CSs of message abandonment were registered.Literal translation is translating literally a lexical item, an idiom, a compound word or structure from L1/L3 to L2 (Dörnyei and Scott 1997). For instance,

"'God bless you my children I know that ..., I am sorry because the responsibility of our home is on you ...".

The use of this strategy can be attributed to the low level of Algerian EFL learners who do not have enough words and vocabulary items in English. That may be due to the lack of using the target language inside and outside the classrooms. Learners perhaps are not exposed to English except for short period of time each week. Moreover, the nature of the educational system and teaching methods which do not emphasize the role of interaction and communication in the classroom may affect the use of this strategy. The effect of the native language is an important factor that may forcelearners to think in Arabic and resort to literal translation. One way to explain this result is the idea that perhaps the use of literal translation is due to the developmental stage of their interlanguage, what Skinner (1957) calls (negative transfer). Thus, the effect of mother tongue interference is manifested in all cases of literal translation where students translate from L1 to L2.

According to Dörnyei and Scott (1997), message abandonment is leaving a message unfinished because of some language difficulty.It should be noted that learners used (103) strategies of this kind with the percentage of $(7.3 \%)$ For instance,

Student $C$ :if you if you ,...,..,.., e:r the prophet asked $u$ s and tell to take care of your love e:r...,...,...,., .

The use of this strategy may be attributed to low level in English that the majority of learners suffer from. The limited linguistic resources can be another reason behind the use of this strategy. Inhibition may be an additional motive which leads students to avoid and abandon their messages. They are probably afraid of making errors as it is argued by Al Hosni (2014). Moreover, the nature of topics and task type which may be not common and preferable for some students may be another reason behind the use of abandonment strategy. Shyness, stress, individual differences and personal factors may play role in these findings.

This table also reported that learners employed the use of all-purpose words, appeal for help, self-correction, approximation, and circumlocution with less frequency than the previous strategies.First, (25) instances of self- 
correction strategies were used by learners in their oral production. It is linked to making self-initiated corrections in one's own speechas it's suggested byDörnyei and Scott (1997). For example,

Student A argues: so, Good morning everybody hi, so let's your..., that is your mark you have 5/10.

There are many causes that possibly lead students to employ self- correction. Such reasons include: the lack of self-confidence and certainty. They also include: the limited vocabulary and linguistic resources in the target language. Besides, learners monitor their production before the output as Krashen (1982) claimed. Personal factors (anxiety, fear and speed of speech) can alsopush the learners to use this strategy.

Second and following Dörnyei's and Scott's (1997) definition, approximation is using a single alternative lexical item(e.g. a superordinate or a related term) which shares semantic features with the target word or structure. In fact, when learners are unable to produce the accurate forms, they resort to alternative ones that share some semantic elements in common with the meaning of the target lexical item. For example:

Learner B claims: you must change the exam point (mark).

The total of (23) cases was the frequency of this strategy in the learners' speech. This may be attributed to the lack of linguistic resources. The nature of the topics may play role in this result. In fact, learners sometimes can't produce the appropriate words. Therefore, theyincorporate alternative ones that share common semantic elements/features with the target word. One interpretation can be suggested is that despite the difficulties that learners face in finding the accurate lexical items, they try to communicate by using alternatives and this is a good for developing communicative competence in the target language which is English in this case.

In addition, topic avoidance is reducing the message by avoiding certain language structures or topics considered problematic language wise or by leaving out some intended elements for a lack of linguistic resources as Dörnyei and Scott (1997) described it, such as the following example,

Student B: no, no. Student C replies: taking mother in nursing house in people can not e:r ..., accept it and can not e:r ..., think e:r ..., /aslan/ (actually) e:r in this e:r ..., in this at this subject /wella maclalabalish/ ( or I do not know).....

It is another intermediate strategy used by Algerian EFL learners. The number of (22) strategiesof topic avoidance are registered in their speech. The most important reasons that lead to the use of this strategy include: thelack of linguistic repertoire, the difficulty of tasks and the nature of topics, the low level of learners and inhibition. Fear of making errors and shyness perhaps are also among the motives that motivate learners to avoid speaking.

According to Dörnyei and Scott (1997) appeal for help occurs when learners turn to the interlocutor for assistance by asking an explicit question concerning a gap in one's L2 knowledge. For instance,

Student A: /kifash nequlu neqdru lmjhudaat/ (how do we say to appreciate the efforts?)

The frequency of appeal of help was (38) instances with the percentage of $(2.7 \%)$ from the total number of CSs that were used in the two tasks. On the basis of the same factor (the lack of lexical items), we also anticipated that learners made use of this strategy. In addition, probably cultural factor may force learners to appeal for assistance. That is because learners live in a society where charity cooperation and help exist among them.

Furthermore, the use of all-purpose words is also among the intermediate CSs employed by the students. Fifty nine CSs is the frequency ofthis strategy from the total number of cases yielded by the scenario and interview. It registers(4.2\%) from the percentages of all CSs used by learners. It was defined by Dörnyei and Scott (1997)as extending a general, "empty" lexical item to contexts where specific words are lacking by using expressions like (things, everything, something and stuffs). For instance,

Student A: Let me tell you something e:r...Do not be mad about me...,..., I want to do something I want ... it is not a stupid thing ...,...,farming is not something e:r...,.

It has been noticed that the use of all-purpose words is not frequently used. That may be attributed to the learners' lack of awareness in problem solving strategies or devices. One more explanation may be the fact that this strategy is not highlighted and used by teachers in the classroom. This can be justified by claiming that the majority of learners who participate in this study are low level students. These (9) strategies can be used by the intermediate or some advanced participants.

Moreover, the use of similar soundings words, circumlocution, foreignising, and word coinagestrategies were less frequently used strategies comparing to the previous ones.Dörnyei and Scott (1997) described the use of similar soundings words as compensating for a lexical item whose form the speaker is unsure of with a word (either existing or non-existing) which sounds more or less like the target item. For example,

Student A says: I did not accept instead of (expect).

Sixteeninstances of this strategy are encountered in the learners' speech. This can be attributed to the memory failure. It may be due to the difficulty of some vocabulary items thatare used in the task. The cohort model or the activation of similar sounding words may be another reason behind its use. In addition, is another justification for the use of this type of strategythe speed of speech and personal factors (shyness and anxiety) possibly are another justification for the employment of such type of strategy.

Circumlocutionalso was not highly used by learners. Following Dörnyei and Scott (1997),itis exemplifying, 
illustrating or describing the properties of the target object or action, such as:

Student A: would you like me to have a very successful life great job, great money and everything ..., (to succeed and to be rich).

Circumlocution occurs (10) times with the percentage of $(0.75 \%)$. In fact, it is used when learners fail to find the right word, so they describe it through using different lexical items asDörnyei and Scott (1997) stated. This probably because the effect of teaching methods that do not highlight the role of circumlocution, or possibly the nature of tasks that do not demand such type of strategy. In addition,this can be attributed to the students' choice who do not prefer to communicate using other words instead they keep quite which is not good. The lack of linguistic resources may be another reason behind this result. These findings are inconsistent with the results concluded by z Tarone (1981-1983) and Haastrup and Phillipson (1983). The latter researchers claimed that circumlocution and word coinage were highly employed by the learners in communication.

Another significant finding is that foreignising and word coinage were among the least used strategies by students. Threecases of foreignising were registered and two other ones were found regarding word coinage. Foreignising is based on using an L1/L3 word by adjusting it to L2 phonology (i.e. with a L2 pronunciation) and/or morphology. The following example is taken from the results of the current study'.

Student B: I taught about it and I have started the /inskripshen/(registration) from French (inscription which means registration).

The use of this strategy may be attributed to the impact of French language. That is because Algeria is a multilingual community where many languages interact (Arabic, Kabyle, and French) in addition to English. Learners do not use this strategy more frequently probably the words in the topics were not difficult for them.

Correspondingly, word coinage is not largely employed strategy by the students. It deals with the act of creating a non-existing L2 words by applying a supposed L2 rule to an existing L2 word as Dörnyei and Scott (1997) described it, such as:

Student A: you should go to e: r..., so I will be sured (sure) for labout your health.

These results are consistent with Tan's, Fariza's, and Jaradat's ones (2012) who stated that this strategy was not largely used by the learners. The nature of topics and tasks which demand new words that are not known or familiar to the learners can motivate students to use this strategy. In addition, the interference of L1 or errors within the language itself that lead students to overgeneralize the rules, can be another reason behind its use. Another way of interpretation is that probably the simplicity and familiarity of the topics that were given to learners which lead them do not use word coinage.

6.2 Findings Related to Research Question 2: Are there statistically significant differences in choosing and using the communication strategies of the interview and scenario?

Table (2): Percentages of CSs Used by Algerian EFL Learners in Scenario and Interview Separately.

\begin{tabular}{|l|c|c|c|c|c|c|}
\hline \multirow{2}{*}{ Strategy } & \multicolumn{3}{|c|}{ Scenario } & \multicolumn{3}{c|}{ Interview } \\
\cline { 2 - 7 } & Rank & Frequency & percentage $\%$ & Rank & frequency & percentage $\%$ \\
\hline Repetition & 1 & 333 & $57.4 \%$ & 1 & 346 & $41.8 \%$ \\
\hline Code switching & 5 & 18 & $3.1 \%$ & 2 & 154 & $18.6 \%$ \\
\hline Use of fillers & 2 & 96 & $16.6 \%$ & 5 & 54 & $6.5 \%$ \\
\hline Use of all-purpose words & 8 & 9 & $1.6 \%$ & 6 & 50 & $6.0 \%$ \\
\hline Self- correction & 7 & 10 & $1.7 \%$ & 9 & 15 & $1.8 \%$ \\
\hline Message abandonment & 3 & 42 & 7.2 & 4 & 61 & $7.4 \%$ \\
\hline Topic avoidance & 10 & 4 & $0.7 \%$ & 8 & 18 & $2.2 \%$ \\
\hline Use of similar sounding words & 9 & 7 & $1.2 \%$ & 11 & 9 & $1.1 \%$ \\
\hline Approximation & 6 & 13 & $2.2 \%$ & 10 & 10 & $1.2 \%$ \\
\hline Literal translation & 3 & 42 & $7.2 \%$ & 3 & 66 & $8.0 \%$ \\
\hline Circumlocution & 14 & 1 & $0.2 \%$ & 11 & 9 & $1.1 \%$ \\
\hline Appeal for help & 11 & 2 & $0.5 \%$ & 7 & 35 & $4.2 \%$ \\
\hline Foreignising & 12 & 3 & $0.3 \%$ & 13 & 1 & $0.1 \%$ \\
\hline \multicolumn{1}{|c|}{ Word coinage } & 12 & 2 & $0.3 \%$ & 14 & 0 & $0.0 \%$ \\
\hline \multicolumn{1}{r|}{ Total } & - & $\mathbf{5 8 2}$ & $100.0 \%$ & - & $\mathbf{8 2 8}$ & $100.0 \%$ \\
\hline
\end{tabular}

Table (2) shows that the CSs used by the Algerian group in scenario and interview tasks separately. The similarities and the differences that exist between them in terms of the choice and use of strategies are presented in table (2). The findings of question (2) which deals with the impact of task type on learners' choice and use of CSs,reveal a difference in the choice of CSs used in the two tasks and quantitative inferential differences in CSs's frequency and use between the two tasks.

To begin with, the task type may have an impact on the choice (quality) of strategies. Word coinage is used in the scenario with the percentage of $(0.3 \%)$, but it is not the case in the interview. It has been noticed that the 
majority of strategies' types are the same, except for word coinage and this may create slight difference between the two tasks regarding the choice of strategies. Thesefindings affected the choice of CSs.Poulisse (1990) found out that the sampled students employedseveral CSs in four communication tasks: photo description (1), description of drawings in L1 and L2 (2), retelling of stories (3), and an oral interview (4).For instance, the students employed analytic strategies (circumlocution and paraphrase) in the first task, while in the third and fourth tasks they used holistic strategies (superordinate, coordinate and subordinate) and transfer strategies. The results of the present study are consistent with the results concluded by Poulisse (1990). Task demands, context, time constraints, the learning pattern adopted for each task (group work for the discussion task and pair work for the description task) possibly played role on the choice and use of CSs generated in each task.

In addition, learners choose direct types of CSs more than indirect and interactional ones. They prefer to solve their problems directly. However, in terms of CSs use, they employ indirect strategy more frequently (repetition). That may be due to the impact of culture, which leads them to be indirect.

Based on table (2), the interview registers (828)cases of CSs, the frequency that is significantly higher compared to (580) instances in the scenario. This may be attributed to the difficulty of interview task which probably requires more linguistic repertoire. These findings are consistent with the findings concluded by GhoutKhenoune (2012). The latter scholars found that their subjects used various CSs with different frequencies in two communication tasks: picture description task and free discussion task. They claimed that task demands, context, time constraints and the learning pattern adopted for each task (group work for the discussion task and pair work for the description task) possibly influenced the use of CSs.In the present study, the presence of the interlocutor seem to be relevant.

Table (2) presents another striking feature. It is represented in the differences between scenario and interview in the total frequency of using CSs. First, the full number of CSs used in the interview registers(828) out of (1048) instances. At this point, one canclaim that the task of interview is more difficult,challenging, and cognitively demanding. Therefore, learners use many CSs to meet the task objectives.

In addition, interview and scenario tasks belong to two different types of discourse. In the scenario task, the subjects are involved in the topics. They feel free to choose theirideas. The fact that theyare divided into groups of four or five students, two students are asked to argue against two others. They produce less CSs, because it has been noticed that some students donot participate, while others are more active and communicate most of the time. Further, the topics of scenario require to be against something which may not be the case in reality. The idea of imagining your self-taking your mother to the nursing home is not easy for learners to accept the role, this can affect the use of CSs.However, in the task of interview, the participants are forced to answer the questions that the interlocutor asked. Thus, they use more CSs especially repetition to gain time, because the topics are spontaneously. The researchers found that they are less emotionally involved in the topic. As a result, they limit themselves to repetition, topic avoidance and code-switching whenthey havelack of the appropriate words.Indeed, it can be considered as a justificationwhy the students resorted to ahigh number of CSs in the interview comparing to the scenario.

Thechoice and use of CSs possibly are influenced by the context of the tasks. For example, the context of interview probably is not agreeable, adequate, and favorablefor learners, because they are constricted by the questions and they have to answer them in a limited period of time, the teacher can't wait them think about their ideas for a long time. Therefore, they use more repetition to gain time, topic avoidance and code- switching to avoid making errors and appeal for help from the teacher. The difficulty of such type of tasks can be another reason behind this result,it is not the case in the scenariowhere the learners are involved ina debate between friends that share the same level and belong to the same social group particularly. This may justify why studentsuse less CSs in the scenario. They are not affected by anxiety, shyness and fear like in the interview which lead them resort more frequently to reduction strategies (repetition and topic avoidance).

Furthermore, time allotted for interview and scenario is approximately the same from five to ten minutes in the interview and from twenty minutes to thirty minutes in the scenario. However, they do not exploit the time equally. In the interview, learners make use of all the period of time, because they are face to face with the teacher. While in thescenario task, they end it rapidly, and some of them do not participate. In addition, when learners facedifficultiesthey abandon the task.

In the current study, two various patterns are investigated. Those patterns include: the conversation between the teacher and the student in the interviewand groups of learners in the scenariotask.As far as the researchersknow, patterns mayaffect the choice and use of CSs in each task. In this respect, the number of turns produced by learners produced a high number of turnsin the interview comparing to the scenario. This can be attributed to the role of interlocutor (teacher) who provides them with more opportunities to speak in the interview, and he/sheasks the studentsquestions and motivates them to speak. However, in the scenario,some advanced learners try to speak and use CSs, while the weak students avoid communication and keep silent all the time. The important number of turns in theinterview can justifythe frequency of strategies generated in this task.

In brief, learners employ approximately the same types of CSsin the two tasks, except for word coinage which 
is used in interview, but not in scenario. Table(2)shows that except for one category (the use of fillers), almost the same type of reduction strategies arefrequently used by the participants in the two different tasks. These four strategies are: repetition, code -switching, literal translation and message abandonment. Their frequency rank is from (1-5) as Table(2) shows. These results can be interpreted by stating that thestudents possibly are not skillful in speaking English.

To conclude what has been stated earlier, the results of question two indicate that the task type influences thechoice and use of CSs used by learners, but the effect of task type on the choice of CSs is weak in comparison with their use. In addition, they revealthe importance and difficulty of interviewtask in EFL classes which motivate learners to employ a large number of CSs.

Accordingly, there are statistically significant differences between the scenario and interview in terms of using CSs. Some of them are more frequently used in the task of interview, but their frequenciesare less in the scenario. This means that task type mayhas an impact on the use of CSs. These findings are consistent with the findings concluded by Kaivanpanah et al. (2012). The latter researcher found that the task type influences the use (quantity) of CSs. Code- switching,the use of all-purpose words, topic avoidance, circumlocution, and appeal for help register a large number in favor of the interviews. This means that the use of these strategies raise in the task of the interview. The table below demonstrates the inferential results of question two.

Table (3):The Differences and Similarities between the Scenario and the Interview in Selecting and Using the CSs by the Algerian Group.

\begin{tabular}{|l|c|c|c|c|c|c|}
\hline \multirow{2}{*}{ Strategy Type } & \multicolumn{2}{|c|}{ Scenario } & \multicolumn{2}{c|}{ Interview } & \multirow{2}{*}{ T Value } & \multirow{2}{*}{ Sig. } \\
\cline { 2 - 6 } & Mean & SD. deviation & Mean & SD. deviation & & \multicolumn{2}{|c|}{. } \\
\hline Repetition & 11.1000 & 6.72284 & 11.5333 & 3.72997 & -.309 & .759 \\
\hline Code switching & .6000 & 1.67332 & 5.1333 & 5.78186 & -4.125 & $.000^{* *}$ \\
\hline Use of fillers & 3.2000 & 3.12278 & 1.8000 & 2.45511 & 1.930 & .058 \\
\hline Use of all-purpose words & .3000 & .74971 & 1.6667 & 1.80676 & -3.827 & $.000^{* *}$ \\
\hline Self- correction & .3333 & .60648 & .5000 & .77682 & -.926 & .358 \\
\hline Message abandonment & 1.4000 & 1.42877 & 2.0333 & 1.37674 & -1.748 & .086 \\
\hline Topic avoidance & .1333 & .43417 & .6000 & .81368 & -2.771 & $.007 * *$ \\
\hline Use of similar sounding words & .2333 & .50401 & .3000 & .65126 & -.443 & .659 \\
\hline Approximation & .4333 & .81720 & .3333 & .60648 & .538 & .592 \\
\hline Literal translation & 1.4000 & 2.369675 & 2.2000 & 1.88277 & -1.441 & .155 \\
\hline Circumlocution & .0333 & .18257 & .3000 & .53498 & -2.584 & $.012 *$ \\
\hline Appeal for help & .1000 & .30513 & 1.1667 & 1.57750 & -3.636 & $.001 * *$ \\
\hline Foreignising & .0667 & .25371 & .0333 & .18257 & .584 & .561 \\
\hline Word coinage & .0667 & .25371 & .0000 & .00000 & 1.439 & .155 \\
\hline Total & $\mathbf{1 9 . 3 3 3 3}$ & $\mathbf{1 1 . 4 7 8 1 2}$ & $\mathbf{2 7 . 6 0 0 0}$ & $\mathbf{9 . 8 7 7 1 8}$ & $\mathbf{- 2 . 9 9 0}$ & $\mathbf{. 0 0 4}$ \\
\hline
\end{tabular}

The mean of code- switching increases from (.6000) in the task of scenario to (5.133) in the interview as Table (3)demonstrates. One of the most interesting finding is the effect of mother tongue/Arabic which increases the variety of strategy use. For instance, code- switching is widely influenced by the mother tongue interference. At this point, inhibition, stress, fear and anxietyare personal factors that affect students' motivation to switch. Especially in this task where they are supposed to face the teacher and talk to him face to face. The same for the use of all-purpose words, topic avoidance, appeal for help and circumlocution, their frequencies increase in the task of interview. Their high number of occurrences in this task is expected, because of the nature of interview which requires the subjects to talk spontaneously and use probably more difficult vocabulary items. This result can be interpreted as the task of interview is perhaps more difficult than the scenario. It demands a large number of strategies, more vocabulary and linguistic repertoire. Possibly it is due to the interview task in which the teacher interferes more than in the scenario. Another reason is that learners are probablyused to daily classroom activities that focus on scenario rather than interview. It is supposed that these reasons lead to the present findings. Running into quick conclusion is not the aim of this study. Perhaps, the topics in the tasks may play role in the use of these strategies. In addition, it can be the teaching methods that do not highlight the task of interview that lead to this result. However, there are no statistical differences between the scenarios and interviews in using the rest of the other strategies.

To recap, it can be said that the task type has an effect on the use of CSs, since it has been noticed that some strategies are frequently used in the task of interview, but they do not register high numbers in the task of scenario. However, it has a weak impact on the choice of strategies, because the majority of strategies used in the two tasks are of the same types, except for word coinage as stated earlier. The results can't be generalized. That is attributed to the study's limitations (e.g. sample) 


\section{Conclusion, Implications, and Recommendations}

It was found that learners usemany CSs in both tasks. This may be attributed to the learners' low proficiency level in English. It was found that the task type has an impact on the choice and use of CSs, but it is proved that its effect on the choice of CSs is weak and limited as Ghout- Khenoune (2012) claimed in her study, where she argued that the impact of task type on the choice of CSs is not significant. Interview and scenario tasks have an effect on the use and frequency of CSs employed by the learners, because it has been noticed that learners resort to more CSs in the interview task than in the scenario one. Furthermore, it was found that learners frequently use the same reduction strategies in both tasks, namely repetition, messageabandonment,literal translation, and code-switching. This may be attributed to the fact that they share common linguistic repertoire and employ the same types of CSs when communicating in the two tasks. However, the high frequency of repetition strategies in both tasks can indicate their low level in English and their lack of strategic competence. Thus, it will be better if the teachers help,motivate and guidethe students to use achievement strategies when they have limited linguistic knowledge. In addition, they need to raise their awareness toward the use of less frequently used strategies in this study, namely approximation, circumlocution and appeal for assistance toward using CSs in the target language instead of native one. Indeed, running into quick decisions is not the study's objective, the topics in the tasks may play role in the choice and use of these strategies. The teaching methods that do not highlight the task of interview also probably lead to these findings. The results can't be generalized to all students of English at the Algerian Universities. Yet, we still hope they will be an interesting reference for future researchers in the field of CSs among EFL learners in Algeria. The researchers recommend conducting studies about the effect of task on the choice and use of CSs, especially contrastive studies among Algerian EFL learners in the Algerian and other contexts are needed.

\section{References}

Ahmed, Sabri (2018). A Study of Communication Strategies Employed by Radfan collegeEFL Students in their Classroom Interactions. An International Journal of English Language, Literature and Literary Theory, 7(3).

Ait Eldjoudi, Ouasila (2015), The Effect of Oral Communication Strategies Instruction on EFL Learners' Anxiety during Oral Sessions. Published MA Thesis, The University of Bejaia, Algeria.

Al Hosni, Samira (2014), Speaking Difficulties Encountered by Young EFL Learners. International Journal on Studies in English Language and Literature (IJSELL), 2(6), 22-30.

Alloui, Meriem (2015), The Role of Communicative Strategies in Developing English Foreign Language Learners' Oral Proficiency. Published MA Thesis, The University of Biskra, Algeria.

Bialystok, Ellen (1990), Communication Strategies: A Psychological Analysis of Second Language Use. Oxford: Blackwell.

Bialystok, Ellen (1983), Some Factors in the Selection and Implementation of Communication Strategies. In C. Faerch and G. Kasper (eds.), Strategies in Interlanguage Communication. London: Longman.

Canale, Michael. and Merrill. Swain (1980), Theoretical Bases of Communicative Approaches to Second Language Teaching and Testing. Applied Linguistics, 1(1), 1-47.

Dörnyei, Zoltan. and Scott, M. (1997), Review Article: Communication Strategies in a Second Language: Definitions and Taxonomies. Language Learning, 47(1), 173-210.

Dörnyei, Zoltan. and Körmos, J. (1998). Problem-Solving Mechanisms in L2 Communication. Studies in Second Language Acquisition, 20 (3), 349-385.

Faerch, C. and G. Kasper (1983a), Plans and Strategies in Foreign Language Communication. In C. Faerch and G. Kasper (eds.) Strategies in Interlanguage Communication. London: Longman.

Faerch, C. and G. Kasper, (1983b), On Identifying Communication Strategies in Interlanguage Production. In C. Faerch and G. Kasper (eds.), Strategies in Interlanguage Communication. London: Longman.

Ghout-Khenoune, Linda (2012), The Effect of Task Type on Learners' Use of Communication Strategies. Procedia-Social and Behavioral Sciences, 69, 770-779.

Haastrup, K. and R. Phillipson (1983), Achievement strategies in Learner/Native Speaker Interaction. In C. Faerch and G. Kasper (eds.), Strategies in Interlanguage Communication. London: Longman.

Hardianti, Rosi (2016), A Study of EFL Students 'Oral Communication Strategies in Discussions. Indonesian EFL Journal, 2(1), 23-33.

Kaivanpanah, Sh. Yamouthy,P, and Karami, H.(2012), Examining the Effects of Proficiency, Gender, and Task Type on the Use of Communication Strategies. Porta Linguarum, 79-93.

Khanji, Rajai (1996), Two Perspectives in Analyzing Communication Strategies.IRAL XXXI, 2,144-154.

Krashen, S(1982), Principles and Practices in Second Language Acquisition. Oxford: Pergamon. Labarca, A and Khanji, Rajai. (1986), On Communication Strategies Focus on Interaction. SSLA, 8, 68 -79.

Mabry, Anne. (1994), The Communication and Learning Strategies of Five Adult Learners of English as a Second Language. Published Ed Dissertation, Columbia University Teachers.

Maleki, Ataollah. (2010), Techniques to Teach Communication Strategies. Journal of Language Teaching and 
Research, 1, (5), 640-646.

Numata, Mitsuku (2009), The Effects of the Use of Communication and Negotiation Strategies on L2 Acquisition. Published MA Thesis, University of Iowa, Iowa.

Poulisse, N (1990), The Use of Compensatory Strategies by Dutch Learners of English. Dordrecht: Foris.

Poulisse, N. and E. Schils. (1989). The Influence of Task and Proficiency - Related Factors in the Use of Compensatory Strategies: A Quantitative Analysis. Language Learning. 39(1) 15-48.

Rababah, Ghaleb (2001), An Investigation into the Strategic Competence of Arab Learners of English at Jordanian Universities. Published Doctoral Dissertation. The University of Newcastle, United Kingdom.

Rababah, Ghaleb and Bulut, D. (2007), Compensatory Strategies in Arabic as a Second Language. Poznań Studies in Contemporary Linguistics, 43(2), 83-106.

Rababah, Ghaleb (2016), The Effect of Communication Strategy Training on the Development of EFL Learners' Strategic Competence and Oral Communicative Ability. Journal of Psycholinguistic Research, 45(3) 625651.

Rababah, Gh. and Seedhouse, (2004), Communication Strategies and Message Transmission with Arab Learners of English in Jordan. Annual Review of Education, CommunicationandLanguageSciences, $\mathbf{1}$ [online].Retrievedfromhttp://research.ncl.ac.uk/ARECLS/vol1_d ocuments/Ghaleb\&Seedhouse/Ghaleb\&Seedhouse.htm

Rababah, Ghaleb (2005), Communication Problems Facing Arab Learners of English. Journal of Language and Learning, 3(1), 1740-4983.

Rosas, Maritza (2018), L2 learners' Use of Communication Strategies as Affected by the Task Type,RevistaSignos. Estudios de Linguistica,51(96), 107-131.

Selinker, Larry (1972), Interlanguage. IRAL, 10, 209 -231.

Skinner, B.F. (1957). Verbal behavior. New York: Appleton -Century Crofts.

Shtavika, Elvir (2018), The Task Type Effect on the Use of Communication Strategies.

Tan, K. Fariza, N, and Jaradat, M.N. (2012), Communication Strategies among EFL Students - an Examination of Frequency of Use and Types of Strategies Used. GEMA Online ${ }^{\text {TM }}$ Journal of Language Studies, 12(3).

Tarone, Elaine (1980), Communication Strategies, Foreigner Talk and Repair in Interlanguage. Language Learning, 30,417-31.

Tarone, Elaine (1981-1983), Some Thoughts on the Notion of Communicative Strategies.TESOL Quarterly, 15, 285-95.

Tarone, E. (1977), Conscious Communication Strategies in Interlanguage: A progress report. In H. Brown, C. Yario and R. Crymes (eds.), On TESOL '77.194 - 203). Washington DC: TESOL. 